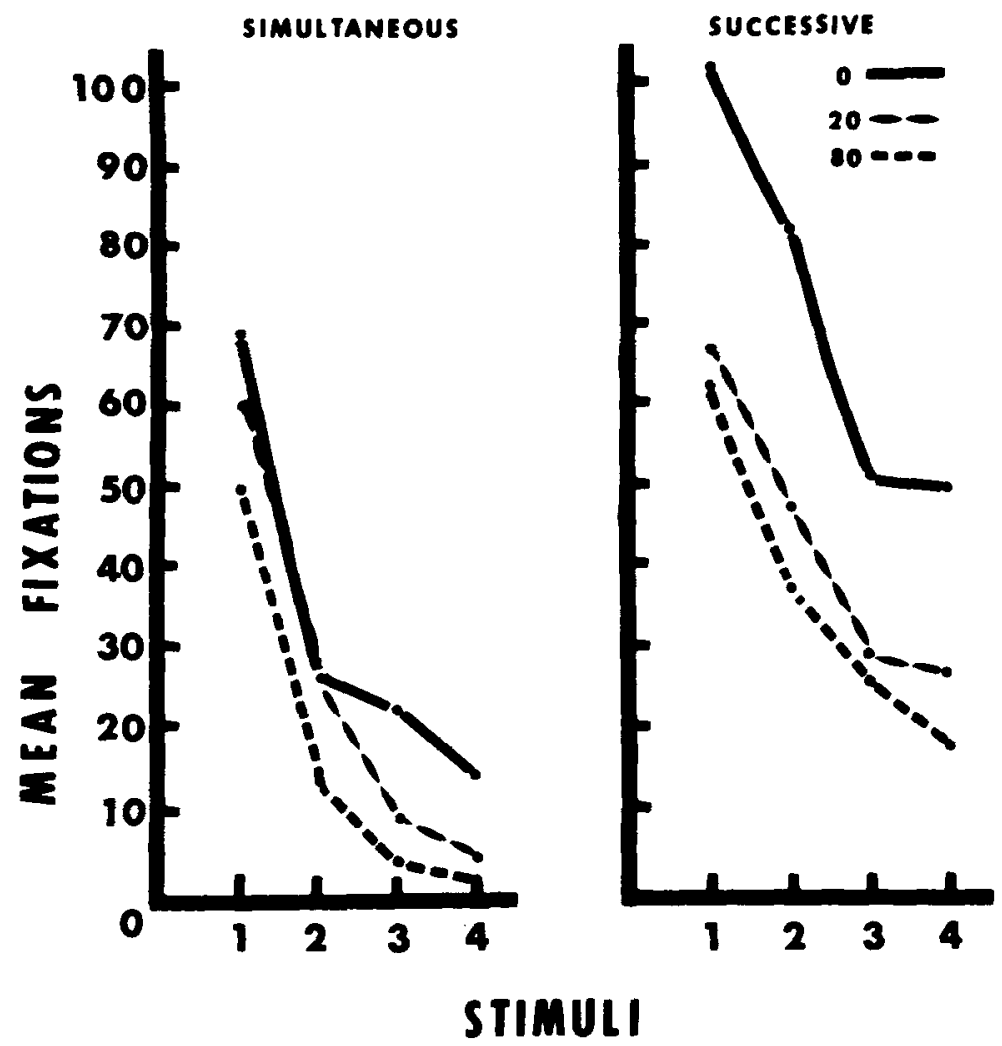

is a two-stage process. The first involves familiarization with stimulus and response contingencies in the task; the second is the solution to the problem involved.

Fixation selectivity during training transferred to selectivity on the second task. If $\mathbf{S}$ fixated redundant form stimuli more often than redundant line stimuli during training, he chose and fixated form stimuli more often during transfer. The same held for line stimuli. All Ss in Groups 2,3,5, and 6 , choosing square during transfer (17 of 20), fixated the triangle more than the oblique line during training. Of the three Ss choosing vertical line during transfer, two fixated the oblique line more than the triangle during training. While the differences between fixation frequencies of redundant stimuli were small, the consistency of fixation patterns from one $S$ to the next raises the interesting possibility that differential fixation frequency of related redundant stimuli, when presented with compound stimuli, may provide an estimate of which aspect of the compound is exerting more stimulus control.

\section{REFERENCES}

EDWARDS, W. Experimental design in psychological research. New York: Hblt, Rinehart, \& Winston, 1960.

GOULD, J. D. Pattern recognition and eye-movement parameters. Perception \& Psychophysics, 1967, 2, 399-407.

KAPLAN, I, \& SCHOENFELD, W. Oculomotor patterns during solution of visually presented
ROBERT E. PHILLIPS, SCOTT B. $B E N T S O N,{ }^{2}$ and PAUL H. BLANEY, University of Minnesota, Minneapolis, Minn. 55455

This experiment compared imitation of male and female models under a vicarious-reinforcement (VR) and a combination $V R /$ direct-reinforcement (DR) condition. Both sexes were used as $S$ s, and female $S s$ performed significantly better than did male Ss. The sex of the model was only significant in the $V R$ condition, where the female model was superior. The VR-DR treatment proved to be significantly more effective than $V R$ alone.

Vicarious reinforcement (VR) is the

\title{
Direct reinforcement, sex of model, sex of subject, and learning by vicarious reinforcement ${ }^{1}$
}

Fig. 1. Distribution of fixations to each transfer stimulus for simultaneous and succeasive ( $80 /$ no-go) discrimination for each training group $(0,20,80$ training trials).

anagrams. Journal of Experimental Psychology, $1966,77,447-451$.

LINDQUIST, E. F. Design and analysis of expertments in psycholosy and education. Boston: Houghton-Mifllin, 1956.

MACKWORTH, N. H., MORANDI, A. J. The gaze selects informative detalls within pictures. Perception \& Psychophysics, 1967, 2, 547-551.

PREMACK, D., \& COLLIER, G. Duration of looking and number of looks as dependent variables. Paychonomic Science, 1966, 4, 81-82.

SCHROEDER, S. R. Selective eye movements to simultaneously presented stimuli during discrimination. Perception \& Psychophysics, in press, $a$.

SCHROEDER, S. R. Effects of cue factors on selective eye movement patterns during successive discrimination. Perceptual \& Motor Skills, in press, b.

SCHROEDER, S. R., \& HOLLAND, J. G. Reinforcement of cye movement with concurrent schedules. Joumal of the Experimental Analysis of Behavior, in press.

TRABASSO, T., \& BOWER, G. Attention in learning: Theory and research. New York: Wiley, 1968.

\section{NOTES}

1. This research was supported by OE Contract No. 4-10-58 and was conducted while the author was a postdoctoral fellow at the Learning Research and Development Center, University of Pittsburgh. observation of contingent reinforcement for certain responses of a model. Research on VR has demonstrated it to be more effective in producing imitation than has observation of a nonreinforced model, and, as a result, VR has been the object of considerable recent research (cf. the review of Flanders, 1968). As yet, however, no research has been conducted on model characteristics that may effect leaming by VR. One of the most obvious model characteristics to investigate is sex, and Bandura, Ross, \& Ross (1961) have hypothesized that, because of past reinforcement history, "one would expect ... subjects to imitate the behavior of a same sex model to a greater degree than the model of the opposite sex [p. 575]." However, the little research on sex-of-model effects with nonreinforced 
models have not demonstrated any dependable effects (Flanders, 1968).

The present study is an attempt to investigate the effect of sex of the model on imitation when the model is reinforced (e.g., VR). It may be that Bandura et al's hypothesis is more relevant to a reinforced model than to a nonreinforced one. Therefore, this experiment will test the hypothesis that same-sex models are more effective in producing imitation by VR. In addition, this experiment will also test the hypothesis that the addition of direct reinforcement (DR) to VR results in more effective learning. Marston (1966) has stated that "... direct reinforcement is ineffective during acquisition with VR [p. 554]." However, his conclusion was based on the use of very few DRs, and it appeared unlikely that VR would negate the effectiveness of DR.

The two hypotheses were tested in a verbal-leaming situation similar to that used by Marston (1966). The procedure has been described in detail in a previous study (Phillips, 1968) and uses a taped simulated group as the model. The $S$ is instructed that he is to discover the class of words used most frequently by the taped group and to say words of that same class when signaled. The $S$ then responds alternately with the taped group. The VR consists of a taped "Good," for each "human" noun on the tape, and the DR consists of the E saying, "Good," for each human noun said by the $S$.

\section{METHOD}

The design of this study was a 2 by 2 by 3 factorial. The first factor was sex of the model, and the second factor was sex of the $S$. The third factor was reinforcement with three levels: no reinforcement (NR), vicarious reinforcement (VR), and VR plus direct reinforcement (VR-DR). In the NR treatment, there are no reinforcements on the tape or to the S. In the VR treatment, every human noun on the tape is followed by a "Good." In the VR-DR treatment, every human noun on the tape is followed by a "Good," and every human noun said by the $S$ is followed by a "Good."

The taped model consists of a group of nine members (either all males or all females). The $S$ was required to respond in turn with the taped model, and each exposure to the model and the subsequent response by the $S$ was considered a trial. The nine members of the taped group said words in turn, and $50 \%$ of their responses were human nouns. There were 30 trials, and the percentage of human nouns increased with each block of 5 trials, e.g., $0 \%, 20 \%, 40 \%, 60 \%, 80 \%$, and $100 \%$.

Sixty male and 60 female volunteers from an introductory psychology class served as Ss. Each treatment group was assigned randomly an equal number of males and females. Each $S$ was run individually in a small room containing a microphone and a small signal light. Following the initial instructions, $E$ retired to an adjacent room and thereafter communicated with $S$ only via an intercom. Both $\mathrm{E}$ and $\mathrm{S}$ wore earphones. One channel of a stereo tape recorder was used to present recorded material (the model ) to $S$; the other channel served as an amplifier for E's communications to $S$.

The instructions to the Ss were that they were to say a word whenever their signal light flashed, and that during part of the experiment they were to respond alternately with a tape recording of other persons performing the same task. The Ss were also told, "One class of words will occur more often than any other in the subjects' responses. Your task is to discover what that class of words is and to give words of that same class."

\section{RESULTS}

The means and standard deviations of CRs for each treatment are presented in Table 1. The analysis of variance on this data indicates that reinforcement and sex of $S$ are the only significant effects $[F(2,108)=13.30, p<.01$ and $\mathrm{F}(1,108)=8.68, \quad \mathrm{p}<.01$, respectively $]$. However, the Reinforcement by Sex of Model interaction approaches significance $[F(2,108)=3.03, p<.055]$.

The hypotheses that VR-DR $>$ VR $>$ NR were tested by the use of $t$ tests. The results indicate that the VR-DR mean is significantly greater than the VR mean $[t(78)=2.36, \mathrm{p}<.05]$, and

Table 1

Means and Standard Deviations of CRs for Each Treatment

\begin{tabular}{|c|c|c|c|c|c|c|}
\hline \multirow{3}{*}{$\begin{array}{l}\text { Reinforcement } \\
\text { Sex of S }\end{array}$} & \multicolumn{4}{|c|}{ Male Taped Model } & & \\
\hline & \multicolumn{2}{|c|}{ NR } & \multicolumn{2}{|c|}{ VR } & \multicolumn{2}{|c|}{$\mathrm{VR}-\mathrm{DR}$} \\
\hline & $\mathbf{M}$ & $\mathbf{F}$ & $\mathbf{M}$ & $\mathbf{F}$ & $M$ & $\mathbf{F}$ \\
\hline $\begin{array}{l}\mathrm{M} \\
\mathrm{SD}\end{array}$ & $\begin{array}{l}7.4 \\
5.61\end{array}$ & $\begin{array}{l}8.9 \\
4.92\end{array}$ & $\begin{array}{l}8.2 \\
4.96\end{array}$ & $\begin{array}{r}10.4 \\
7.23\end{array}$ & $\begin{array}{c}14.5 \\
7.19\end{array}$ & $\begin{array}{c}17.9 \\
5.43\end{array}$ \\
\hline $\begin{array}{l}M \\
S D\end{array}$ & $\begin{array}{l}8.1 \\
6.77\end{array}$ & $\begin{array}{l}\text { emale } \\
10.1 \\
5.63\end{array}$ & $\begin{array}{l}\text { del } \\
10.5 \\
6.57\end{array}$ & $\begin{array}{r}18.9 \\
4.45\end{array}$ & $\begin{array}{c}12.5 \\
6.62\end{array}$ & $\begin{array}{c}17.6 \\
6.56\end{array}$ \\
\hline
\end{tabular}

that the VR mean is significantly greater than the NR mean $[\mathrm{t}(78)=2.34, \mathrm{p}<.05]$.

The Reinforcement by Sex of Model interaction was further investigated by the use of orthogonal comparisons of the means. The results indicate that the male and female taped models do not differ significantly in the NR and VR-DR treatments $[t(108)=0.49, p>.05$ and $t(108)=0.59, \quad p>.05, \quad$ respectively] However, the difference in the means of the male and female models in the VR treatment was significant $[\mathrm{t}(108)=2.81$, $\mathrm{p}<.01]$, with the female model being superior.

The nonsignificant Sex of $S$ by Sex of Model interaction indicates that the hypothesis of greater effectiveness for same-sex models must be rejected. The results also indicate that female Ss performed better than did male Ss. The responses to a postexperimental questionnaire suggest a possible explanation of these results. The questionnaire asked for likeability ratings for the $E$ on the tape (male), the real $E$ (male), and the taped models. The only major result was that female Ss rated the $E$ on the tape higher in likeability than did the male Ss (a point biserial $r$ of .32 between sex of $S$ and rating of $E, p<.01$ ). It appears that the superiority of the female Ss, at least in the reinforcement treatments, may be the result of finding the male E's "Good" more reinforcing than did the male Ss.

Finally, it is clear that Marston's (1966) conclusion that DR is ineffective when VR is present cannot be generalized to all VR situations. The $D R$ proved to be quite effective in this situation, for there was a significant improvement in performance with the addition of only 32 DRs (on the average) to the 225 VRs. This is consistent with Phillips's (1968) demonstration that, under comparable conditions, DR is more effective than is VR.

\section{REFERENCES}

BANDURA, A., ROSS, D., \& ROSS, S. A Transmission of aggression through imitation of aggressive models. Joumal of Abnormal \& Social Psychology, 1961, 63, 575-582.

FLANDERS, J. P. A review of research on imitative behavior. Psychological Bulletin, 1968, 69, 316-337.

MARSTON, A. R. Determinants of the effects of vicarious reinforcement. Journal of Experimental Psychology, 1966, 71, 550-558. PHILLIPS, R. E. A comparison of direct and vicarious reinforcement and an investigation of methodological variables. Joumal of Experimental Psychology, 1968, 78, 666-669. NOTES

1. This research was supported by a grant from the Graduate School, University of Minnesota. An earlier version of this article was presented as a paper at the 1969 American Psychological Association convention in Washington, D.C.

2. Now at Southern Illinois University. 